\title{
Novel Control Method on Unified Power Quality Conditioner (UPQC) for Harmonic Distribution Using PSO-Fuzzy Logic
}

\author{
Y.Mallikharjuna Rao ${ }^{1}$, B Sarath Chandra ${ }^{2,}$ Dr.N.C.Kotaiah ${ }^{3}$ \\ \{ymallieee@gmail.com ${ }^{1}$, sarath.boppudi@gmail.com ${ }^{2}$, nellurikotaiah@gmail.com ${ }^{3}$ \} \\ Assistant Professor, Department of EEE, RVR \& JC College of Engineering, Guntur, A.P, India ${ }^{1,2}$ \\ Professor, Department of EEE, RVR \& JC College of Engineering, Guntur, A.P, India ${ }^{3}$
}

\begin{abstract}
In this paper novel control method on unified power quality improvement for harmonic distribution using PSO-Fuzzy logic is implemented. There are various types of compensators such as parallel power quality compensator and series power quality compensatorwhichimproves the power quality. In this proposed work, control algorithm is developed on unified power quality conditioner. The entire algorithm is divided into three stages, in stage -1 all the parameters will be initialized and in stage- 2 process computing the upper and lower boundary's of $\mathrm{X}$ and $\mathrm{Y}$ is done. At last in stage- 3 the process of commuting value of $\mathrm{z}$ is done and output is obtained. The simulation results show that fuzzy controller based particle swarm optimization will improve the accuracy, effectiveness and superiority.
\end{abstract}

Keywords: Unified power quality conditioner (UPQC); optimal volt-ampere (VA) rating/loading; displacement angle control (DAC); reactive power sharing; voltage leak and swell.

\section{Introduction}

In modern daysnon-linear loads are increasing amazingly and many of the loads to a great extent reliant on it. Non-linear loads are TVs, bend heaters, printing and fax machines, microwaves, rectifiers, inverters, electronic contraptions, speed drives, AC, and so on. All these non-linear loads present in the linesare of power quality issues [1]. The steadiness of any electrical gadget is to a great extent represented by the gracefully voltage and flow waveforms. In this event the principal waveform is sinusoidal, and its sounds are sinusoidal too then these happen in vital products of the central waveform thus provided power is weakening. Because of these consonant distribution produced by nonlinear loads, a few issues are caused in the machines which are utilized in our motivation like overheating of the engine, increment in misfortunes, changeless harm of gear is the most pessimistic scenario, high mistake in meter perusing, and so on. Subsequently alleviation of non-liner loadonload side or source side is a major test for a power engineer.

Because of the sounds presentation in the lines by the nonlinear load's different issues are produced, for example, voltage swell, voltage droop, glimmer happening in voltage, and so on therefore proficiency of intensity gracefully corrupts. In past, detached channels utilizing tuned LC segments were in especially use to improve the nature of intensity by expelling 
voltage and current sounds. However, its utilization is restricted these days since they have a significant expense, reverberation, enormous size. Some of the issues can be compensated using Active powerfilter (APF) which has been in pattern these days [2].

In electrical power framework power gadgets assume a significant job. In dispersion framework it has three viewpoint initial one is that presents important modern and household types of gear, second one is that makes issues, third one is that help to take care of issues [3]. Presentday's cutting edge semiconductor exchanging gadgets, for example, controlled rectifiers, Uninterruptible Power Supplies (UPS), curve heaters and so on are generally utilized especially in local and mechanical loads. These non direct loads make power quality issues, for example, voltage list, voltage swell, voltage interference, voltage glimmers, and voltage spikes and so on. Such poor power quality causes increment in power misfortunes and other noteworthy variations from the norm in appropriation sides.

Along these lines, it is essential to keep up an elevated requirement of intensity quality. Prior uninvolved channels were utilized to take care of intensity quality issues. Anyway due to certain confinements of aloof channels, present day's custom power gadgets are utilized to take care of intensity quality issues in circulation side. The remunerating custom power gadgets are utilized for dynamic sifting, load adjusting, power factor improvement and voltage controlling (droop/swell). There are three sorts of custom power gadgets: Distribution Static Compensator (DSTATCOM), Dynamic Voltage Restorer (DVR) and Unified Power Quality Conditioner (UPQC) [4-5].

Earlier, there is staggering utilization of complex frameworks with innovatively propelled part, for example, non-direct load, uninterruptable power flexibly, rectifier loads, power hardware gadgets in household just as mechanical territory. These parts influence the source as well as unclean the power gracefully with their characteristics. This will repeat the age of different power quality unsettling influences, for example, commotion, voltage sounds, current music, homeless people, and so forth. The impact of all these power quality issues are consistently relies on reason for unsettling influences and its occurrence.IEC and IEEE plan different universal gauges for power quality wellbeing and mindfulness.

The answers for all the power quality systems will likewise relies on its reasons for events, area, timespan impact, recurrence of event. These all adjustments is based on conduct of flexibly framework likewise influence on the end clients hardware. The present power framework is for the most part as three stage three wire or three stage four wire bringing with huge cutoff to voltage source with source impedance and having a blend of different kinds of loads. According to the IEEE guidelines and perspective on perfect state of intensity frameworks an unadulterated and equalization three stage voltage of steady greatness tought to be furnished to customer with as less as conceivable power quality issues.

Anyway with the utilization of intensity hardware gadgets and a few non-direct loads, responsive, single stage and unbalance three stage load making structure of framework progressively complex with a few power quality issues. At a similar side in ongoing year a few dynamic techniques for improving power quality have been featured with their quick reaction and little structure, for example, extraordinary dynamic power channels and bound together power quality conditioner which can be utilized to evacuate power quality issues for both arrangement and shunt side of the frameworks. 


\section{Upqc General Block Diagram Configuration}

The dependability of force is progressively worried about power providers and end-users. In the last part of the 1980s, power electronic gadgets, creating the new stacking supplies and microchip dependent on controls which accomplished a few premises for improving power quality. Further spotlight on the presentation of force age frameworks which has been given to the proceeding with expansion in the gadgets, like high proficiency, variable speed engines and shunt capacitors, because of expanding power factor to decrease power misfortune. Therefore, symphonious levels of the force frameworks are expanding and numerous individuals stress over future effects on the ability of the framework [2].

End clients are more mindful of issues with nature of the force. Utilities clients are better mindful of issues like breaks, interferences, difficulties and transient changes to improve the force supply. So all PCs in the organization are interconnected. Incorporated cycles simply that stacking hardware has undeniably more significant ramifications for disappointment of every segment. Strangely, the gadgets that are introduced for expanded efficiency likewise regularly influence extra force quality issues to the gadget that is the most influenced by the gadgets and basic force disturbances.

The effective activity and control of the machines is progressively reliant upon the nature of the energy when all cycles are robotized. Force quality can be portrayed as a force supply that permits a legitimate working of the electric gadget. Truly client driven issue and the end client reference point is liked for the nature of force [3]. Subsequently any force issues that show in current or recurrence, breakdown of client gear or voltage deviations that bring about disappointment can be grouped into the nature of the force supply issues.

Current Flexible Alternating Transmission System is utilized to give straightforward and unadulterated force, for example the waveform of unadulterated sinusoidal voltage. In the flow electrical organization, there is utilization of various transmission devices; those are Interline Power Flow Controller (IPFC), Unified Power Quality Controller (UPQC), Static Synchronous Compensator (STATCOM) and Static Synchronous Series Compensator (SSSC, etc. Transmission gadgets were intended to work the transmission framework which are refreshed.

These are utilized on the force conveyance frameworks as "Custom Power Devices". Active Filter (AF), Dynamic Voltage Restorer (DVR), Static Synchronous Compensator (DSTATCOM) and Unified Power Quality Conditioner (UPQC) are probably the most generally utilized force gadgets. With the assistance of these gadgets, the quality issues were significantly limited, in light of lower cost and the more modest size of its quick reaction of DVR made it as amazing and dependable gadgets [4]. Dissemination frameworks are having such countless issues like sounds, swell, drifters and holes. In the dispersed framework, issues are prompts voltage spill. The schematic outline of UPQC is introduced in Fig. 1. The UPQC comprises of three modules, which are shunt converter, arrangement converter, and transformer. The shunt converter manages the current remuneration. 


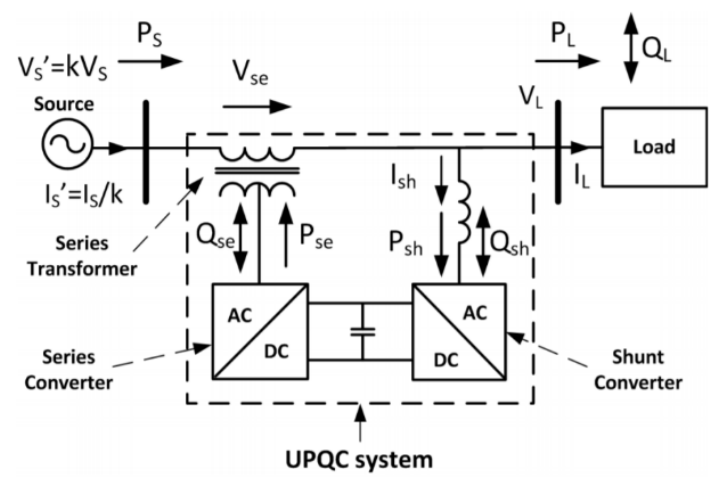

Fig. 1: UPQC general block diagram configuration

The course of action converter can source voltage. The transformer handles the course of action induced voltage. Due to the satisfactory execution in compensating all voltage and current PQ issues, UPQC gets perhaps the most engaging plans. Experts have considered about restricting the total voltage loadings of the UPQC system using different procedures. The improvement of the hard and fast voltage loadings is refined to the impediment of growing the assessments of the overall UPQC system. Actually, the assessing part of the UPQC structure has seldom thought to be the force electronic converters and transformers.

\section{Upqc Based Sources of Power Qulity}

\subsection{Power Electronic Devices}

The nonlinear load power electronic gadgets are given as Choppers, Rectifiers, Inverters and so on. All these will leak the volatge if they are not protetcted. Simialry, harmonic distortion is created for these types of loads.

\section{IT and Office Equipment}

IT and office equipments consists of Switch Mode Power Supply (SMPS) which creates an harmonic distortion to aviod the voltage leaks. In the third, fifth and seventh level the harmonics are distributed in triple way storage system.

\section{Arcing Devices}

In this devices electric arcing gadgets, electric circular furnaces and electric discharge lighters will be availble which are basically known as non direct charges. The arcing devices are moderated with each other based on the adjustment of circular segment furnances. They work with devices under different variant modes. The devices are frequently triggered when nearby systems are tolerated and electronic systems are protected very effectively. 


\section{Switching of Load}

Transient operation is obtained based on the exchange of effect of the voltage. An impact is obtained based on the huge single-stage stack which is a transient. The loads are controlled based on the different mechanical systems which are controlled electrically.

\section{Starting of Large Motor}

Large motor is utlized based on the concept of acceptance machines which is an vigrourus cocept. The current standrad will increase the load while the motor is operating. Leaks of voltage are organised by the impedance of system.

\section{Sensitive Equipment}

The power quality is variated very slowly when the equipment is manufactured and arranged in particular format. The power quality events consists of different types of issues based on the hardware systems.

7. Different Damages in Environment and Storm

Light strikes are a wellspring of transient overvoltage's, regularly bringing about disappointments in the force supply organization. There is no requirement for the nearby organization to acquaint the homeless people lightning with strike a conductor. In the event that close to place of the conductor strikes the lightning, drive can be delivered. A close by strike will push up the nearby ground expected prompts nonpartisan current coursing through a far off surface to earth.

\section{UPQC For Harmonic Distribution Using Pso-Fuzzy Logic}

The below figure (2) shows the flow chart of UPQC for harmonic distribution using PSOfuzzy logic. The entire algorithm is divided into three stages, in stage -1 all the parameters will be initialized and in stage- 2 process of computing the upper and lower boundary's of $\mathrm{X}$ and $\mathrm{Y}$ is done. At last in stage- 3 the process of commuting value of $\mathrm{z}$ is done and output is obtained. 


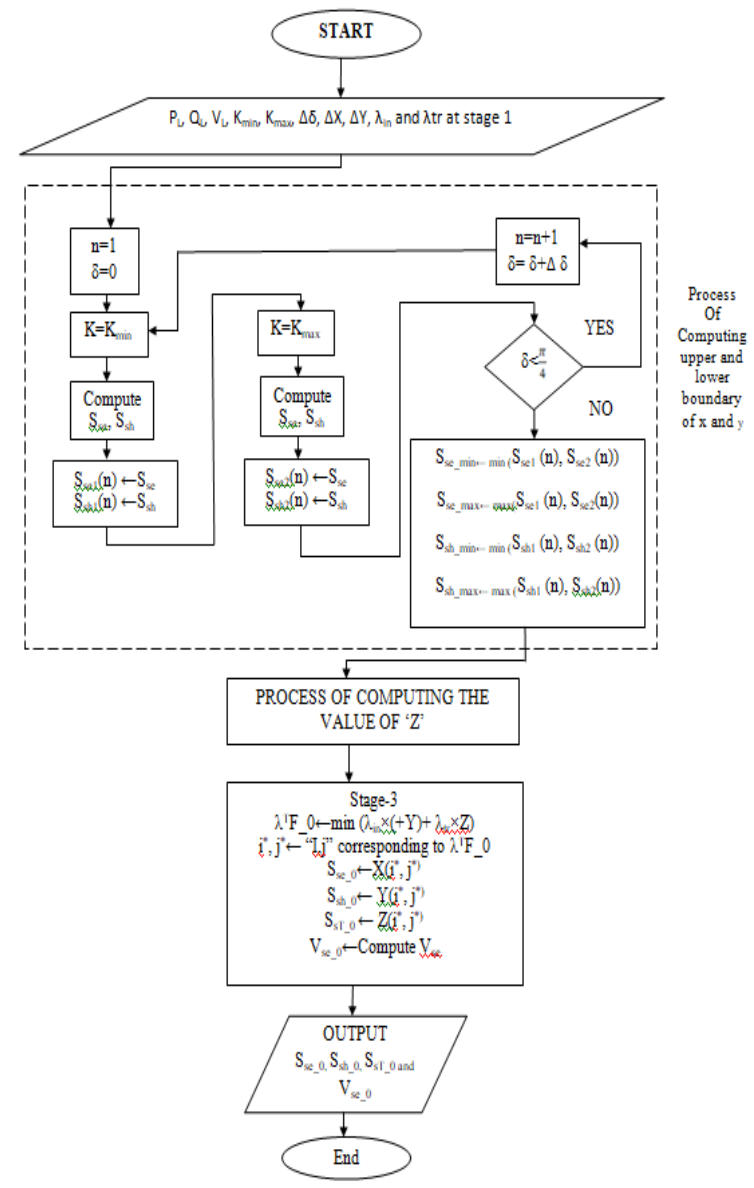

Fig. 2: Flow Chart of Upqc for Harmonic Distribution Using Pso-Fuzzy Logic

Kennedy and Eberhart introduced the Particle Swarm Optimization algorithm technqiue. This technqiue mainly computes the evolutionary behaviour of system in effective way.

The below shows the steps of UPQC operation where mainly 3 parameters of fuzzy controller is involved:

1) A random initial value is assigned to increase the speed and location of every area after the dividing of entire solution intially $\theta_{\mathrm{i}}=\left[\mathrm{k}_{\mathrm{e}}, \mathrm{k}_{\mathrm{ec}}, \mathrm{k}_{\mathrm{u}}\right]^{\mathrm{T}}$. The intial copndition value is represented as $p_{\text {Best }}$ which is nothing but individual extreme value. Minimum error value is obtained for the global extreme value $g_{\text {Best. }}$ All the values of area are recorded at the same time

2) Calculation of Velocity $\mathrm{Vi}(\mathrm{t}+1)$ of particle $\mathrm{i}$ is done.

3) Particle $\mathrm{i}$ is updated as Positioning vector $\mathrm{Xi}(\mathrm{t}+1)$. 
4) Positioning vector $p_{\text {Best }}$ is set to $g_{\text {Best }}$ when If fitness function min (e) $\theta i$ is better than before.

5) The operation will be stop when iteration reaches to the pre-determined one at the same token level. In fuzzy controller the values of ke, kec and ku is optimized.

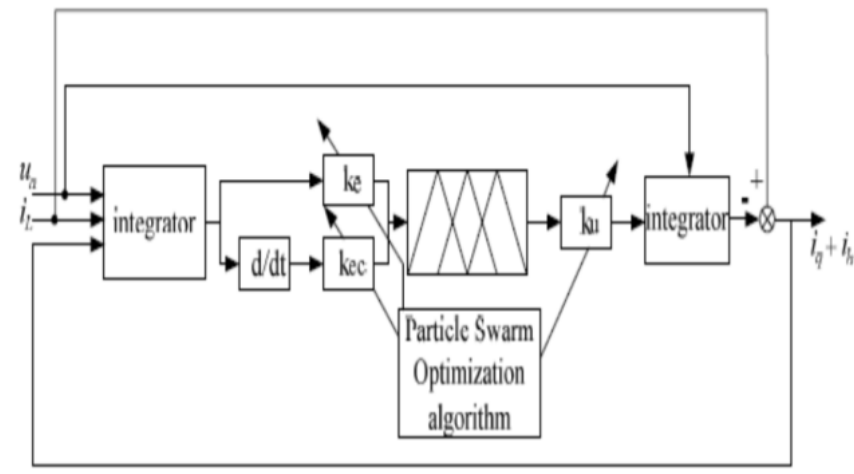

Fig. 3: Principle Of Pso-Fuzzy Controller

Figure (3) shows the principle of PSO-FUZZY controller. In this integrators are used for boost up of signals. PSO algorithm will improve the performance of system.

\section{Results}

The below figure (4) shows the comparison of accuracy for UPQC and UPQC for harmonic distribution using PSO-fuzzy logic. Compared to normal UPQC design, the proposed design gives high accuracy.

ACCURACY

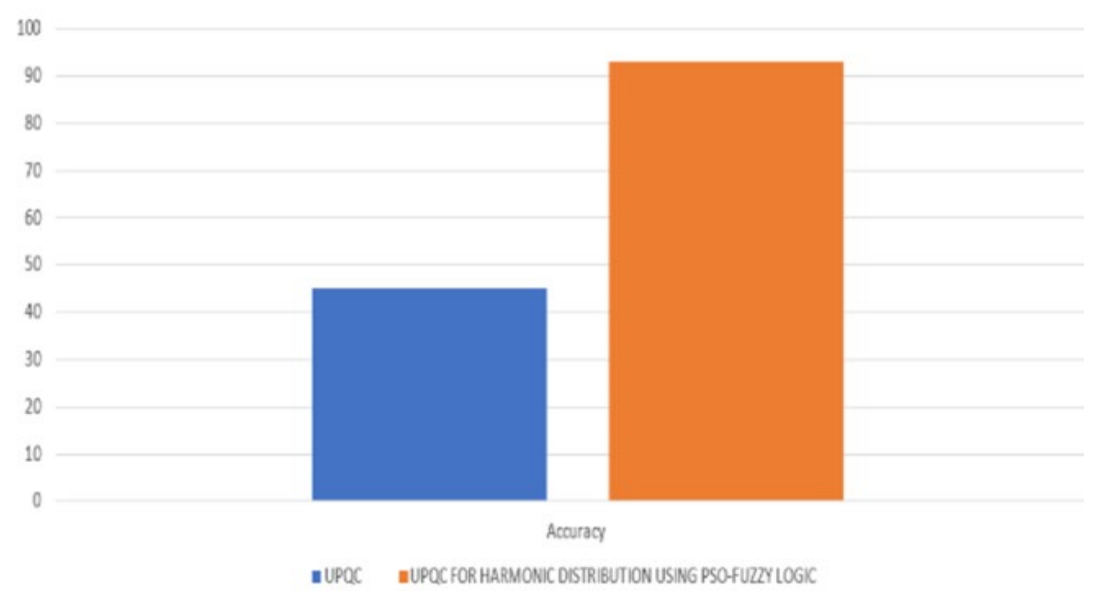

Fig. 4: Accuracy Comparison 


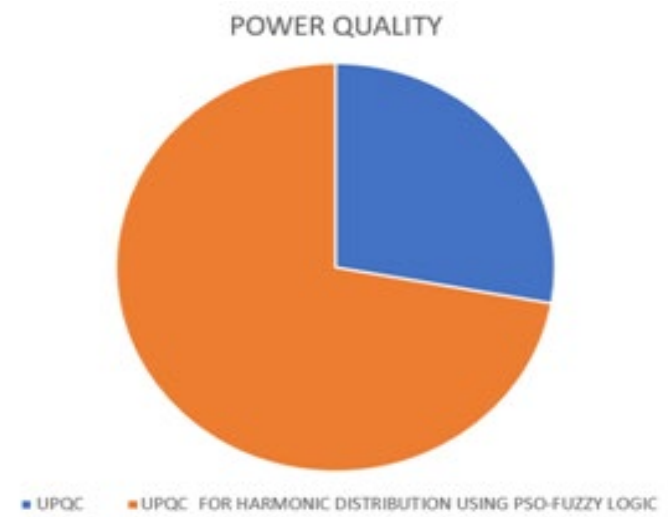

Fig. 5: Power Quality Comparison

The above figure (5) shows the comparison of power quality for UPQC and UPQC for harmonic distribution using PSO-fuzzy logic. Compared to normal UPQC design, the proposed design has good power quality.

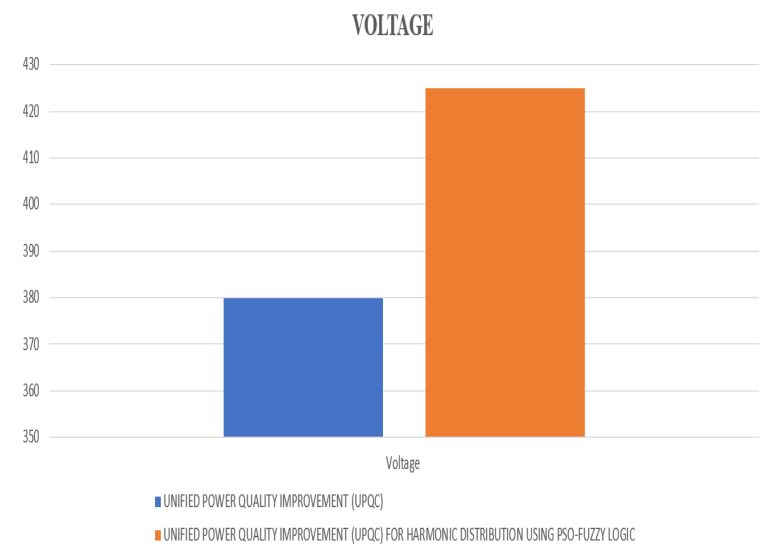

Fig. 6: Comparison of Volatge

The above figure (6) shows the comparison of voltage for UPQC and UPQC for harmonic distribution using PSO-fuzzy logic. UPQC takes $380 \mathrm{~V}$ and UPQC for harmonic distribution using PSO-fuzzy logic is $425 \mathrm{~V}$.

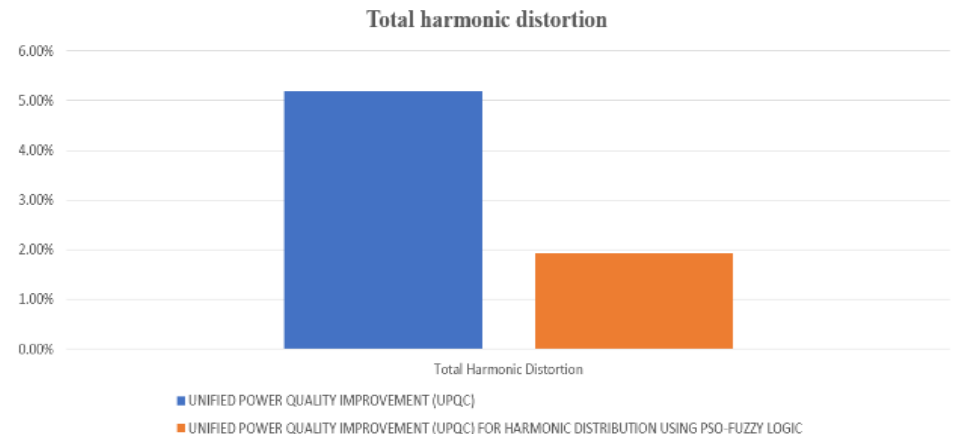

Fig. 7: Total Harmonic Distortion 
The above figure (7) shows the total harmonic distortion of power quality for UPQC and UPQC for harmonic distribution using PSO-fuzzy logic.

In UPQC for harmonic distribution using PSO-fuzzy logic, will maintain the capacitor voltage, terminal voltage of line, reactive power and active power. By using the reference values parameters are controlled and compared with each other. Figure 8(a), (b) and (c) shows the membership function of FC where error, change in error and output is given. Fuzzification, Nonuniform fuzzifier is utilized in the present work. Change is errors are obtained very small when the exact values of error are obtained. Similalry, the the values are divided coarsely when the exact values are large.
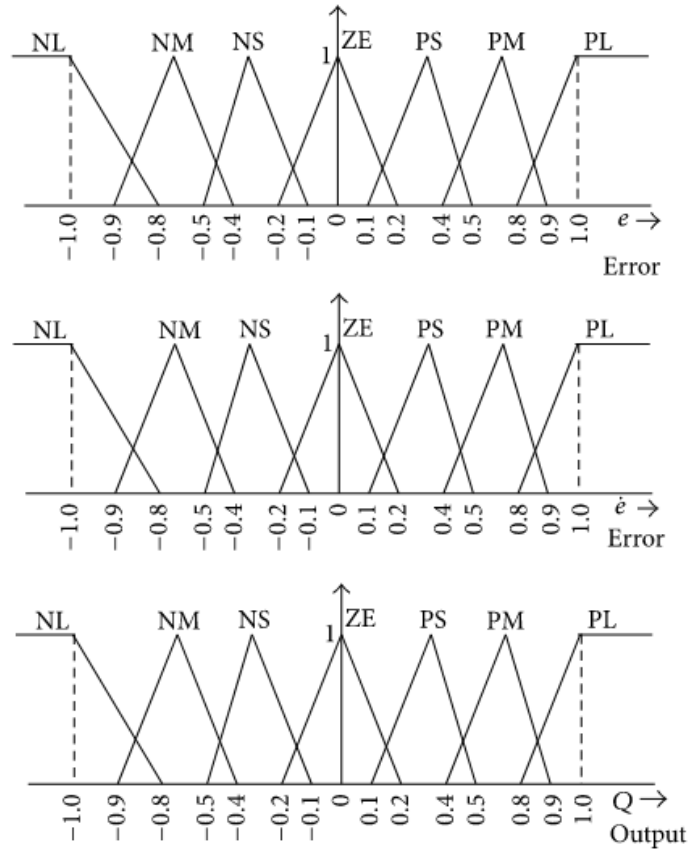

Fig. 8: Membership Function Of Fc: (A) Error (B) Change in Error and (C) Output

\section{Conclusion}

In this paper novel control method on unified power quality improvement for harmonic distribution using PSO-Fuzzy logic is implemented. The entire system is dependent on the Harmonic distortion and voltage control execution which is distribution network. Harmonic voltages are generated by using the harmonic current proliferation in the power systems. DSTATCOM will actually reduce by the use in distribution systems based on nonlinear diode rectifier load. Accuracy, effectiveness and superiority will be improved based on the fuzzy controller based particle swarm optimization. 


\section{References}

[1] Aziz Tashkori, seyyed hosseyn, "Power quality improvement using power electronic transformer based DVR", IEEE Transactions on Power Electronics 2018.

[2] Ray, O, Adda, R, Mishra, Joshi \& SK, "Synchronous- Reference- Frame- Based Control of Switched Boost Inverter for Standalone DC Nano grid Applications", IEEE Transactions on Power Electronics, vol. 28, no. 3, pp. 1219-1233, A 2013.

[3] Barbir, F, "PEM Fuel Cells Theory and Practice $2^{\text {nd }}$ Edition", Elsevier Academic Press, New York, 2012.

[4] Bhumkittipich, K \& Mithulananthan, N, "Performance Enhancement of DVR for Mitigating Voltage Leak/Swell using Vector Control Strategy", Energy Procedia, vol. 9, pp. 366-379, 2011.

[5] Bhuvaneswari \& Charles, S, "Comparison of Three Phase Shunt Active Power Filter Algorithms", International Journal of Computer and Electrical Engineering, vol. 2, no.1, pp. 1793-8163, G 2010.

[6] Kalyan kumar, B \& Mishra, MK, Anil kumar, R, Siva kumar, G, "Compensation of voltage leaks with phase-jumps through DVR with minimum VA rating using PSO based ANFIS controller", International Journal of Swarm Intelligence Research, vol.1, no.3, pp.19-33, 2010.

[7] AlRashidi, MR \& EI-Hawary, ME, "A Survey of Particle Swarm Optimization applications in Electrical power systems", IEEE Transactions on Evolutionary Computation, vol. 13, no.4, pp. 913$918,2009$.

[8] Aredes, M, \& Watanabe, EH, Akagi, H, "Instantaneous Power Theory and Applications to Power Conditioning", John Wiley \& Sons, New Jersey, 2007.

[9] H, Akagi, "Modern active filters and traditional passive filters", Bulletin of the polish academy of sciences Technical Sciences, vol. 54, no. 3, pp. 255-269, 2006.

[10] H, Akagi, "Active Harmonic Filters", Proceedings of the IEEE, vol. 93, no. 12, pp. 2128-2141, H 2005. 